\title{
Grey Relational Analysis of Carbon Emission and Energy Consumption from the Perspective of Economic Growth in Guangdong Province
}

\author{
Jianxiang Zhang \\ Foshan University, Foshan 528000, Guangdong, China \\ Email: zjx9612082021@163.com
}

\begin{abstract}
The relationship among economy, energy and carbon emission in Guangdong province is analyzed by using grey relational analysis method. Studies show that coal consumption is the main reason for the increase in carbon dioxide emissions in Guangdong province after its rapid economic growth. Therefore, to slow down the carbon dioxide emissions in Guangdong province, the first step is to improve the energy consumption structure.
\end{abstract}

Keywords: Guangdong Province, carbon emission, grey relational analysis

\section{Introduction}

Located at the southernmost tip of China, Guangdong is the central maritime hub of the South China Sea and one of the country's earliest pilot areas for reform. Guangdong province undertakes national innovation, research and implementation in some key areas, accumulating good development experience and historical projects for the region and the country. ${ }^{[1]}$ Since its establishment, Guangdong province has enjoyed social and economic prosperity, with its per capita GDP rising from 2,307.32 yuan in 1989 to 9,4172.00 yuan in 2019. Meanwhile, per capita energy consumption increased from 0.69 tons of ordinary coal in 1998 to 2.56 tons in 2019 and per capita carbon emissions per ton of ordinary coal increased from 0.43 tons in 1998 to 1.98 tons in 2019, while quickly measuring economic growth, energy consumption and carbon emissions. The increasingly common mode of economic growth has led to the continuous interruption of "power failure", "oil shortage" and "coal shortage" in Guangdong Province, which has seriously hindered the high carbon emissions caused by economic growth and rapid development. Before the emergence of revolutionary technologies, how to effectively reduce energy consumption and carbon emissions while driving the economic growth of Guangdong province is a key factor in the economic transformation of Guangdong Province. To achieve this goal, it is necessary to clarify the province's energy consumption and carbon emissions. ${ }^{[2]}$

Guangdong Province has fulfilled the historic mission of economic and environmental construction. Guangdong has pledged to cut carbon dioxide by 40-45 percent from 2005 levels by 2020. By 2022, average carbon emissions will fall to 21.24 percent. Guangdong is facing the challenge of major technological revolution and short-term energy efficiency improvement, and needs to achieve the strategic goal of the relationship between energy consumption, carbon emissions and economic growth. ${ }^{[3]}$ The author makes a detailed study of the restrictive factors and motivations of energy conservation and emission reduction in Guangdong Province, and studies the gap and policies in the field of energy conservation and emission reduction in Guangdong Province without affecting economic growth. This paper will provide a framework for the systematic analysis of key energy saving and policy decision-making in Guangdong Province, and help to establish a scientific innovation system for regional and even national energy saving and emission reduction policies.

\section{Research Methods}

\subsection{Vector autoregression model}

Vector Autoregression (VAR) was proposed by ChristopherSims in 1980. Classical economic model is a structural model created under the guidance of economic theory, while VAR model is a model that uses unstructured methods to create variables among variables. The model consists of several functions. Each endogenous variable can be used as a function of the next value of all the endogenous variables. The mathematical form is as follows:

$$
\begin{gathered}
\mathrm{y}_{\mathrm{t}}=\Phi_{1} \mathrm{y}_{\mathrm{t}-1}+\ldots \ldots+\Phi_{\mathrm{p}} \mathrm{y}_{\mathrm{t}-\mathrm{p}}+\mathrm{Hx}_{\mathrm{t}}+\varepsilon_{\mathrm{t}} \\
\mathrm{t}=1,2, \ldots, \mathrm{T}
\end{gathered}
$$


The above formula, $\mathrm{y}_{\mathrm{t}}$ is the vector of $\mathrm{n}$-dimensional endogenous variables, $\varepsilon_{\mathrm{t}}$ is the random perturbed variable, $\mathrm{p}$ is lag intervals for Endogenous, $\Phi_{\mathrm{p}}$ is the coefficient matrix of $\mathrm{n} \times \mathrm{n}$.

\subsection{Impulse response function}

Impulse response function (IRF) refers to current and future endogenous variable values or strong effects on the system if the concept of random error is buffeted by a standard deviation representing interaction with the variable.

\subsection{Grey relational grades}

Grey relational analysis is a new approach to exploring uncertain problems with little data and insufficient information. It is also a practical mathematical discipline, studying information that is partly clear, partly ambiguous, and partly error-free. "Some known information, some unknown information" and a small sample of unreliable systems were used as part of the investigation. First, obtain basic information by creating and developing known knowledge areas, understand how the system is managed, correctly interpret the laws of evolution, and execute them effectively. For the world, there is no white system (information is completely clear) or black system (information is completely ambiguous), only grey relational. Therefore, the grey relational theory develops in parallel with the width of grey relational.

\section{Empirical analysis of energy consumption, carbon emissions and economic growth}

\subsection{Stationarity, cointegration and Granger causality test}

Sequential stability testing should be performed before installing the VAR model, using the standard ADF (Augented Dickey-Fuller Test) method. The test results showed that at the significance level of $10 \%$, the logarithms of $\ln \mathrm{Y}$, $\ln E$ and $\operatorname{lnCO}_{2}$ sequences were unstable, and the corresponding first sequence was in the sequence, so they were a whole. Published for $\ln \mathrm{Y} \sim \mathrm{I}(1), \ln \mathrm{E} \sim \mathrm{I}(1), \operatorname{lnCO} \sim \mathrm{I}(1)$.

According to LR, SC and HQ assumptions, the maximum order sequence is 2, so VAR model (2) is selected. The results of The Johansen joint test show that the null hypothesis "has a weight of 0 ", namely the subsequent tests and the maximum number of tests, is rejected at the factor level of 5\%. The similarity between the three variables is a long-term harmonious relationship. The results in Table 1 show that unilateral growth is responsible for energy consumption at the critical level of $5 \%$, while carbon emissions and energy consumption are mutually responsible.

Table 1. Granger causality test results

\begin{tabular}{ccc}
\hline The null hypothesis & P values & Check the conclusion \\
\hline LnE is not lnY's Granger cause & 0.2178 & accept \\
$\mathrm{LnY}$ is not lnE's Granger cause & 0.0291 & Refused to \\
$\operatorname{lnCO} \mathrm{I}_{2}$ It's not lnY's Granger & 0.2161 & 0.1812 \\
$\ln \mathrm{Y}$ is not lnCO ${ }_{2}$ Granger cause & 0.0031 & accept \\
$\mathrm{LnCO}_{2}$ is not the cause of lnE's Granger & 0.0012 & Refused to \\
$\mathrm{LnE}$ is not the Granger cause of $\operatorname{lnCO}_{2}$ &
\end{tabular}

\subsection{Establish vector autoregressive model}

According to the previous results $\mathrm{p}=2$, the VAR (2) model was established. The VAR (2) model is written in the matrix form:

$$
\left[\begin{array}{c}
\ln \mathrm{Y} \\
\ln \mathrm{E} \\
\ln \mathrm{CO}_{2}
\end{array}\right]=\left[\begin{array}{lll}
2.562723 & 0.181021 & 01106763 \\
2.562723 & 0.181021 & 0.106763 \\
2.562723 & 0.181021 & 0.106763
\end{array}\right] \times\left[\begin{array}{c}
\ln \mathrm{Y} \\
\ln \mathrm{E} \\
\ln \mathrm{CO}_{2}
\end{array}\right]_{t-1}+\left[\begin{array}{ccc}
-0.580532 & 0.181021 & -0.280721 \\
0.1380191 & -0.24455 & -0.465509 \\
0.032908 & 0.29853 & -0.759045
\end{array}\right] \times\left[\begin{array}{c}
\ln \mathrm{Y} \\
\ln \mathrm{E} \\
\ln \mathrm{CO}_{2}
\end{array}\right]_{t-1}+\left[\begin{array}{c}
0.57175 \\
1.510201 \\
2.175323
\end{array}\right]
$$

The given ratios associated with the three model equations are $0.99304,0.99099$ and 0.99698 respectively, indicating that the model is very accurate. All root AR stability test points are located within the cell. This ensures that the VAR version is stable. Carbon emissions Economic growth is complex and diverse, and in general, three-variable systems are robust and able to analyze responses to stimuli. 


\subsection{Pulse response analysis}

The above is the analysis of whether the external environment is stable. If the external environment changes, the stimulus response function should be used to test the dynamic relationship between the three variables. The results are shown in Table 2 .

\subsubsection{The strong link between economic growth and energy consumption}

If the external environment has a positive influence on energy consumption, the GDP response continues to increase from the first to the seventh period, until the peak of 0.02033 in the seventh period, and then gradually decreases. The positive impact on GDP, i.e., the positive energy consumption response, indicates that growth first decline and then increased. From the beginning of season 5 to after season 10, energy consumption begins to increase. The above results show that energy consumption has a very positive impact on GDP growth. That is, China's economic growth still depends on high energy consumption.

\subsubsection{The close link between economic growth and carbon emissions}

If it had a positive impact on the world's $\mathrm{CO}_{2}$ emissions, GDP would now show zero. Then all reactions after the fourth phase, except for the positive values of the second and third phases, are negative, and the overall GDP response to carbon dioxide is -0.22224 . However, even if increased carbon emissions start to increase GDP, the increase will have a negative impact on the environment. And it will be short-lived with the increase of $\mathrm{CO}_{2}$, serious environmental pollution. Carbon emissions usually have a long-term impact on future GDP growth. If the world has a positive impact on a unit of GDP, carbon offsets in phases one to five will have a positive response and a negative response after the sixth session. This shows that China's economic growth will undoubtedly lead to an increase in carbon dioxide emissions. ${ }^{[4]}$

But in the case of sustainable economic growth, the government will give priority to environmental issues and take relevant environmental protection measures to reduce carbon emissions and environmental pollution. Therefore, in the long run, China's current economic growth is likely to reduce carbon dioxide emissions in the fut

Table 2. Results of the pulse response analysis

\begin{tabular}{|c|c|c|c|c|c|c|}
\hline Period & $\begin{array}{l}\text { Response of } \ln Y \\
\text { to } \ln E\end{array}$ & $\begin{array}{l}\text { Response of } \ln \mathrm{Y} \\
\text { to } \ln \mathrm{CO}_{2}\end{array}$ & $\begin{array}{l}\text { Response of } \ln E \text { to } \\
\ln Y\end{array}$ & 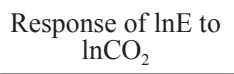 & $\begin{array}{l}\text { Response of } \operatorname{lnCO}{ }_{2} \\
\text { to } \ln Y\end{array}$ & $\begin{array}{l}\text { Response of } \ln \mathrm{CO}_{2} \\
\text { to } \ln \mathrm{E}\end{array}$ \\
\hline 1 & 0.00000 & 0.00000 & 0.00990 & 0.00000 & 0.01533 & 0.02240 \\
\hline 2 & 0.00558 & 0.00243 & 0.01180 & 0.00437 & 0.01897 & 0.0397 \\
\hline 3 & 0.01134 & 0.00105 & 0.00862 & 0.00056 & 0.01555 & 0.03236 \\
\hline 4 & 0.01569 & -0.00552 & 0.00340 & -0.00959 & 0.00890 & 0.03215 \\
\hline 5 & 0.01863 & -0.01531 & -0.00154 & -0.02046 & 0.00168 & 0.03186 \\
\hline 6 & 0.02022 & -0.02581 & -0.00481 & -0.02859 & 0.00440 & 0.03066 \\
\hline 7 & 0.02033 & -0.03530 & -0.00573 & -0.03327 & -0.00747 & 0.01189 \\
\hline 8 & 0.01882 & -0.04292 & -0.00410 & -0.03508 & -0.00932 & 0.02344 \\
\hline 9 & 0.01578 & -0.04833 & -0.00011 & -0.03475 & -0.00747 & 0.01788 \\
\hline 10 & 0.01151 & -0.05145 & 0.00582 & -0.03282 & -0.00298 & 0.01189 \\
\hline Accumulated & 0.13789 & -0.22115 & 0.02326 & -0.18964 & 0.02800 & 0.26145 \\
\hline
\end{tabular}

\subsection{Dynamic relationship between energy consumption and carbon emissions}

If the outside world has a positive impact on carbon dioxide emissions, the energy consumption is 0 at this time, and the maximum at other times is 0.00437 . From phase 4 to 10 , all reactions were negative, with the intensity of negative effects initially increasing and decreasing as phase 8 was below -0.03508 . Therefore, in the long run, carbon emissions have a significant impact on future energy consumption. This is mainly due to environmental pollution caused by the increase in carbon dioxide emissions and the decline in the ratio of oil and coal consumption to energy consumption. If the world has a positive impact on energy consumption, then the current and future carbon emissions response is positive, i.e. the impact of energy consumption leads to a positive long-term impact on carbon emissions, up to 0.03236. Affects the third stage, followed by slow crying. Therefore, high energy consumption (especially for fossil fuels) means that high pollution and high energy consumption have a long-term positive impact on carbon emissions. The results suggest in order not to damage the ecological environment, Guangdong should use clean energy to promote greater and more integrated 
economic growth. ${ }^{[5]}$

\subsection{Establish multiple regression model}

Variables $\ln \mathrm{Y}, \ln \mathrm{E}$ and $\ln \mathrm{CO}_{2}$ were regression, and the regression results were shown in Table 3.

Table 3. $\ln \mathrm{Y}$ and $\ln \mathrm{E}, \ln \mathrm{CO}_{2}$ Regression results

\begin{tabular}{cccc}
\hline Parameter & Coefficient & T statistic & P value \\
\hline $\mathrm{C}$ & -13.829 & -3.081 & 0.000 \\
$\operatorname{lnE}$ & 3.691 & 3.237 & 0.000 \\
$\operatorname{lnCO}{ }_{2}$ & -1.271 & -2.654 & 0.015 \\
\hline
\end{tabular}

$$
\begin{aligned}
\ln Y_{\mathrm{t}} & =-13 .-829+3.69 \ln \mathrm{E}_{\mathrm{t}}-1.271 \ln \mathrm{CO}_{2 \mathrm{t}} \\
\mathrm{t} & =(-3.081)(3.237)(-2.654)
\end{aligned}
$$$$
\mathrm{R}^{2}=0.966173 \mathrm{R}^{2}=0.96424 \mathrm{~F}=499.843
$$

According to the regression results, the $\mathrm{P}$ values of $\ln \mathrm{E}$ and $\operatorname{lnCO}$ in the $\mathrm{T}$ test are both less than 0.05 , which means that energy consumption and carbon emission have a significant impact on economic growth. $\mathrm{R}^{2}=1.987586, \mathrm{~F}=499.843$, $\mathrm{R}^{2}$ is very close to 1 and $\mathrm{F}$ value is very large, indicating that the model fits well. From the regression coefficient, energy consumption is an important factor to promote economic growth. Every 1\% increase in energy consumption leads to an average GDP growth of 3.69\%. Carbon emissions hamper economic growth. For every 1\% increase in carbon emissions, GDP drops by $1.271 \%$ on average.

Table 4. Calculation results of grey correlation degree

\begin{tabular}{cccccc}
\hline $\begin{array}{c}\text { Influencing } \\
\text { factors }\end{array}$ & The GDP total & Urbanization rate & $\begin{array}{c}\text { Proportion of } \\
\text { primary industry }\end{array}$ & $\begin{array}{c}\text { Percentage } \\
\text { of secondary } \\
\text { industry }\end{array}$ & $\begin{array}{c}\text { Proportion of } \\
\text { tertiary industry } \\
\text { consumption per } \\
\text { unit of GDP }\end{array}$ \\
\hline $\begin{array}{c}\text { The calculation } \\
\text { results }\end{array}$ & 0.72 & 0.63 & 0.55 & 0.62 & 0.62 \\
\hline
\end{tabular}

\section{Countermeasure and suggestion}

\subsection{Optimize energy consumption structure and increase the proportion of clean energy}

The province still controls coal consumption as an energy source, with oil accounting for almost 20 percent of annual energy consumption. But empirical analysis confirms that increased oil consumption will hamper economic growth, increased coal consumption will stimulate the economy, and increased energy consumption will further increase carbon dioxide emissions. Energy consumption should be regulated to ensure sustainable economic, social and ecological development. Appropriate reduction or reduction of coal consumption, reduce oil consumption, although the price of clean energy is generally high, but low environmental pollution, high potential value. Guangdong province is rich in wind and solar energy resources. After active exploration, Guangdong province has made the first breakthrough on the road of clean new energy. The development and utilization of clean energy cannot be separated from investment and technological innovation. It should continue to promote the growth of clean energy, increase subsidies to the new energy industry, improve the competitiveness of the market, and actively promote green, low-carbon travel, energy conservation and other environmental protection concepts.

In addition, energy concentration is the main factor to curb carbon emissions, and improving energy consumption is the most obvious effect of emission reduction. To increase support for improving energy efficiency of scientific research investment, enterprise independent innovation, absorbing advanced experience of energy efficiency in other areas and intensify promotion and popularization of related infrastructure, seek cooperation with scientific research institutions, colleges and universities, development or training talents in this way, the energy efficiency of Guangdong province is generally low, and there are many needs to be developed. Further improve energy storage efficiency and reduce regional 
emissions by improving utilization efficiency. ${ }^{[6]}$

\subsection{Comprehensively deepen reform and foster new growth driver}

In Guangdong province, at the end of the 12th Five-Year Plan period and the beginning of the 13th Five-year Plan period, the growth rate of industrial output decreased year by year, and the industry was indeed constralnEd by the growth of carbon dioxide emissions. Industry is an important component of energy consumption and carbon emissions. As industry continues to grow under normal conditions, energy consumption in the industrial sector is also increasing. Assuming that coal and oil are characterized by energy consumption, the total amount of carbon dioxide released into the atmosphere increases. Therefore, it is necessary to accelerate the transformation of economic growth mode, promote strong economic growth and transform to strong economic growth. We will accelerate industrial restructuring, reduce the proportion of new costs in total production costs, and promote rapid growth of industries with low energy consumption and high utilization rate. We will promote the intelligent development of traditional industries, raise the awareness of innovation and learning, promote independent innovation, draw on the advanced experience of carbon-free technologies, implement the concept of green growth, and promote the development cycle of resources, the environment and the economy. In addition, cooperation and exchanges between regions and industries should be promoted so as to improve the flow of energy resources, development concepts and technologies between regions and industries, improve industrial efficiency, and promote the steady growth and development of regional economy and regional economy. We should pay close attention to carbon emissions and explore carbon-neutral development models in light of local conditions.

\subsection{Improve laws on low-carbon economy and innovate low-carbon incentive systems}

Developed countries such as the United Kingdom and the United States have established relatively complete laws and regulations on low-carbon economy. However, the carbon-neutral carbon economy is still in its infancy. There are no independent low-carbon economic laws and regulations in Guangdong Province, so we should increase and improve the minimum carbon emission measures for industrial enterprises based on the environmental protection law. Different laws and regulations are applicable to different types of industrial enterprises. Strengthen monitoring systems for the growth and operation of low-carbon economies, increase participation in green industries, reduce capital investment in energy-intensive and polluting industries, provide job opportunities for downsizing, and promote the introduction of low-carbon solutions. We should implement laws and regulations on coal-free conversion, innovate low-carbon incentive plans, shape carbon emission standards, severely punish enterprises that fail to meet the standards, encourage the development of enterprises with high energy consumption, and implement a selection policy for enterprises that meet the standards, so as to effectively promote the healthy and rapid development of low-carbon enterprises.

\section{Conclusion}

Grey correlation analysis is being used to promote empirical research on the relationship between economic growth, energy consumption improvement and carbon emissions in Guangdong Province. The results were obtalnEd by calculating the correlation of grey degrees among different indexes. In order to reduce the carbon emission of Guangdong province and other cities, the normal energy consumption structure should be established first, and then the industrial structure should be adjusted. Secondly, the rapid economic growth of Guangdong province and the city and the rapid development of the university industry have also increased the overall carbon emissions of Guangdong province and the city. Therefore, while developing the economy, we must first improve energy consumption, improve energy efficiency, transform and upgrade high-energy-consuming industries, and at the same time take advantage of energy and Guangdong's geographical advantages to slow down carbon emissions. Second, we should strengthen industrial innovation and strive to make major breakthroughs in science and technology to develop a large number of new energy sources and a green and low-carbon economy. The third is to speed up the development of emerging industries, especially to reduce the production cost of new energy, new drugs, new chemical and environmental protection industries, reduce the relationship between coal consumption and gray level carbon: emissions 0.831451 , improve the structure and energy consumption. This is partly to accelerate technological change and increase energy efficiency in traditional industries. On the other hand, the contribution of clean energy to economic development will be increased by promoting the development of solar energy and other emerging industries, benefiting Guangdong province and municipalities.

\section{References}

[1] Zhou Di, Wang Wenjie, Chen Zijia. China Environmental Science, 2020, 4012: 5551-5560. 
[2] Xiong Pingping, Cao Shuren, Yang Zhuo. Grey relational analysis of carbon emissions in East China [J]. Journal of Dalian University of Technology (Social Science Edition), 2021, 4201: 36-44.

[3] Hu Xiaofei, Wang Xiuhui, Wu Shuang. Ecological Economy, 2019, 3507: 49-55.

[4] Li Zongtao. Analysis of the relationship between rural economy and agricultural carbon emissions in Qinghai Province based on grey relational degree. Southern agriculture, 2019, 1332: 106-108.

[5] Bian Lihua, Calculation and grey correlation analysis of carbon emission of Qinghai transportation system. China buslnEss theory, 2018, 25: 142-143.

[6] Guo Jingtao. Empirical analysis and research on energy price and energy market under carbon and sulfur emissions. Jiangsu University, 2017. 